\title{
The sharing principle: a way of managing multicultural organisations
}

\author{
R. Rijamampianina* \\ Graduate School of Business Administration, University of the Witwatersrand, \\ PO Box 98, Wits 2050, Republic of South Africa \\ rijamampianina.r@wbs.wits.ac.za \\ T. Maxwell \\ Graduate School of Business Administration, University of the Witwatersrand, \\ PO Box 98, Wits, 2050, Republic of South Africa \\ maxwell.t@wbs.wits.ac.za
}

Received June 2002

\begin{abstract}
Although much has been said in academia on the importance of multiculturalism, cultural clashes in business and the workplace continue to be an issue of growing concern as the world moves toward an interlinked, global economy. Now more than ever, learning to draw on the richness of a kaleidoscopic workforce and to assist all team members in delivering their best efforts is a critical managerial task. This article provides a synopsis of the background to the problem of managing culturally diverse organisations, discusses the influences of cultural diversity on management, and proposes a conceptual framework for managing multicultural organisations through the 'sharing principle'. The challenge for a multicultural learning organisation is to increase the potential benefits of cultural diversity by creating a willingness-toshare attitude - sharing success, sharing mental models, sharing vision, and sharing competence. A real commitment to the sharing principle is essential to effective management in culturally diverse organisations.
\end{abstract}

*To whom all correspondence should be addressed.

\section{Introduction}

With the arrival of global markets and changes in international communication capabilities, organisations must recognise that their environment is changing dramatically (James \& Snell, 1994), and particularly with respect to multicultural places of work. Jaeger (1990) argues that people's assumptions, beliefs, values, interests, needs, and goals are shaped by the culture to which they belong, so they are likely to be fairly deeply rooted. It follows, at least in the short run, that culture cannot be changed to meet the demands of management. Employees' behaviour in an organisation will be guided by the cultures from which they derive. Cultural values are brought into the workplace and have a strong impact on the behaviour of people within the organisation (Jaeger, 1990).

Though the great challenge facing management might be described as the search of 'how' to manage multicultural organisations, prior studies fall short of providing practical guidance for at least the following three reasons:

Research in multicultural management is not sufficiently related to real life.

Many researchers have used short-term groups that existed only for the duration of their studies (e.g., Cox, Lobel, \& McLeod, 1991; Watson \& Kumar, 1992; Watson, Kumar, \& Michaelsen, 1993). Their findings therefore provide little guidance as to what to expect in ongoing organisational groups. Some researchers have been confined to using small sample sizes because organisations are reluctant to participate, and their findings, in turn, are limited (Cox, 1990). Others have employed simplistic tasks in their research (Fenelon \& Megargee, 1971) and/or have used exercises with a game-like quality (Ruhe \& Allen, 1977), having no significant impact on group members' well being. These have limited the relevance of the studies. While comparative studies have demonstrated that culture affects the work-related values and behaviours of its members (e.g., Hofstede, 1984; McCarrey, 1988) and that the differences between cultures can cause difficulties in the multicultural workplace (e.g., Vaid-Raizada, 1985; Tang \& Kirkbride, 1986), there exists little empirical literature on the dynamics of culturally diverse work groups and even less on the effective management of such groups.

The conclusions of existing studies are incongruent.

With regard to the level of performance of diverse groups, some studies have concluded that racial diversity inhibits group performance (Fenelon \& Mergagee, 1971; Ruhe \& Allen, 1977); some find no performance differences between racially diverse and racially homogeneous groups (Matsui, Kakuyama \& Onglatco, 1987); and some conclude that racial diversity enhances the performance of groups (Ruhe \& Eatman, 1977; Watson et al., 1993). With regard to the influence of national, regional and organisational cultures, some specialists argue that national or regional culture is rarely present in the firms (e.g., Maurice, Sellier \& 
Silvestre, 1992) or that it is often overpowered by organisational culture (Ivanier, 1992). Indeed the idea that organisational culture moderates or erases the influence of national or regional culture has been a very popular one. It assumed that employees working for the same organisation even if they are from different countries or regions are more similar than different (Adler, 1991). However, other researchers affirm that national or regional culture is predominant compared with organisational culture (e.g., D’Iribarne, 1986; Meschi \& Roger, 1994).

\section{Multicultural workplaces have proven difficult to research.}

Evers (1991) suggested that the greater the need for comparison, the greater the need to reduce complexity. Consequently - though many analyses serve as useful background information - they are ineffective as recommendations for action. Indeed, the challenge is to isolate the interactions among cultures given a host of other variables in a dynamic system, and it appears possible that much past research went awry because it identified culture as an outcome variable, as a causal variable, or as an indexer of utility functions when such definitions were inaccurate. Simons, Váquez and Harris (1993) point out that it is no longer acceptable to determine one specific set of leadership standards that the 'good manager' can practice to be successful. Relativity and flexibility are the new norms. In addition, there is a warranted fear of misunderstanding as a result of the possible contribution to stereotyping that results from the definition of culture in areas that are likely to be sensitive identity issues. Thus applied cultural studies face grave difficulties in variable definition, data collection, and empirical estimation.

This research addresses the question: How can managers more effectively manage multicultural organisations? It is a theoretical contribution to the debate on multicultural management, based largely on the work of Rijamampianina (1999).

The authors propose an answer to the research question through a management model based on key organisational processes (Section 2), and guiding management principles (Section 3). While the management model could be usefully applied to management in any organisation, it is argued that the guiding principles are most specifically relevant in multicultural contexts.

\section{A model for managing culturally diverse organisations}

Whereas managers have sometimes attempted to initiate organisational change through changes in the structures and policies of an organisation, Rijamampianina (1999) suggests that managers would be more effective were they to focus their efforts on organic processes. The former are static, the latter dynamic. Organisational processes are in action at all times, shaping the organisation and influencing its performance, sometimes in keeping with, and sometimes in opposition to the stated policies and established structures. Thus the practical impact of cultural diversity on management practices would most importantly be identified in organic processes that constitute an organisation. Rijamampianina (1999) continues by suggesting that the bulk of organisational activity can be described by the following four inter-related processes.

- $\quad$ The motivational process. All employees are impacted upon by a range of internal and external motivating forces, which together predispose those employees to think and act as they do under various circumstances. Since different employees have different needs, capabilities and perceived opportunities, it is not surprising that their motivational patterns differ from one another. The alignment of the motivating forces acting on employees is therefore a management challenge of no small proportion. In a multicultural context, where motivational patterns are likely to differ more radically than they are in homogeneous contexts, the challenge is exaggerated.

- The interaction process. Employees arrive at their place of work with a set of assumptions about how the world in which they live operates, a set of opinions about the roles of all the stakeholders in the organisation, and a set of values by which they judge all their experiences. All communications received by employees are evaluated in accordance with their assumptions and attitudes, and all communications delivered by those employees are done so from their own frame of reference. The interaction process is the process by which employees share their views of the world; by which they generate an understanding of their colleagues' assumptions, attitudes and values. In other words, when employees interact, they share their mental models, and such sharing generates the basis of mutual understanding, mutual respect, constructive conflict and trust. Members of organisations in relatively homogeneous work contexts cannot be assumed to share a common set of mental models, so it follows that employees in a multicultural context could begin with vastly different mental models.

- The visioning process. Though many organisations communicate a broad mission or vision statement with their employees, it does not follow that the employees will necessarily share a common understanding of the vision, nor will they necessarily support the vision. The visioning process is ideally one that involves all employees in defining and redefining the essential purpose of the organisation in such a way that it generates a level of alignment in the understanding of the vision, and a level of commitment to the pursuit of the vision. It is obvious that the visioning process can only be effective if the motivation and interaction processes are effective. That is, effective visioning requires a minimum level of shared understanding about the "world" in which the employees live, and a minimum level of alignment of the motivational forces acting on the employees. Once again it is apparent that the increased diversity of multicultural groups determines that the visioning process will represent a 
greater management challenge than it would have in a homogeneous group.

- $\quad$ The learning process. Learning in this context refers to learning that is specifically related to the empowerment of employees in a manner critical to their success in meeting the challenges they face at work. The learning could be formal or informal, specific to a work task or related more generally to the work environment, or based on verbal or written communication. What is important is that it is relevant, 'just-in-time', and sufficient for successful completion of work tasks. Again it is apparent that healthy learning processes are largely dependent on healthy motivation and interaction processes, and that the level of diversity in the workforce determines the difficulty managers are likely to have in keeping those processes healthy.

Rijamampianina (1999) proposed that the organisational processes described above are inter-related (as illustrated in Figure 1), and that successful management of those processes leads to high levels of organisational performance. In section three of this report guiding principles are proposed for successful management of each of the four processes in multicultural contexts.

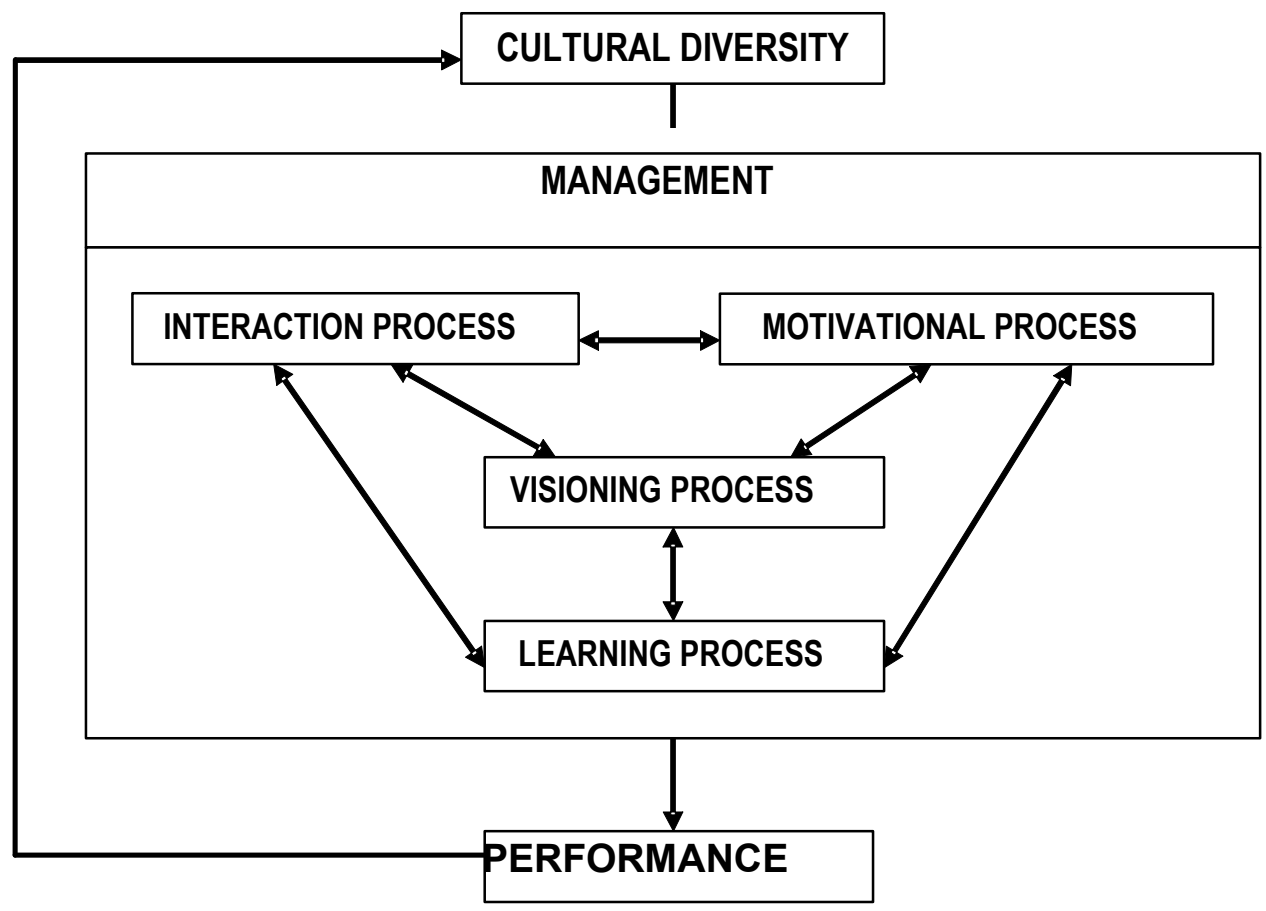

Figure 1: Influences of cultural diversity on management

\section{Guiding principles for multicultural management}

Since diversity in many situations is a fact of life and not a choice, and since the potential benefits of diversity appear to be greater than the potential costs (Cox \& Blake, 1991), the challenge for management is to increase these benefits while decreasing the negative effects of diversity.

In a study aimed primarily at the development of core competence through enhancing multicultural learning, Rijamampianina (1999) proposed that successful organisational learning is dependent on healthy processes of interaction, learning and visioning. Thus he suggested that in the pursuit of high performance in multicultural organisations, managers need to create organisations that:
- Share business successes and failure with employees (motivation process);

- Welcome and encourage mental model sharing (interaction process);

- $\quad$ Support vision creation with employees (visioning process); and

- Encourage core competence development (learning process).

Each of these requirements is discussed in more detail in the following sub-sections, with a focus on guidelines for achieving success in multicultural contexts. 


\section{Motivation process: success sharing}

Success sharing (or gain sharing) grew rapidly as a means of compensation and involvement in U.S. industry (GrahamMoore \& Ross, 1990), arguably because of its effect on the alignment of employee efforts towards meeting organisational objectives. It is a system of management in which an organisation seeks higher levels of performance through the involvement and participation of its people. Employees share (not necessarily financially) in success measured by an improvement in performance. Success sharing also reinforces total quality management, partially because it contains common components, such as identity with, involvement in, and commitment to the business (Wilhelm, 1995).

Two guiding principles emerge from the literature in answer to the question 'How should companies share success with employees in a multicultural context?'

1. Management must be committed to the principle of success sharing, and to accepting the changes that are entailed in introducing and running such a system (Wilhelm, 1995); and

2. The policy devised for success sharing must be fair (Graham-Moore \& Ross, 1990), and the implementation of the policy transparent.

\section{Management commitment}

Thomas and Ely (2001:229) identified three different management perspectives on workforce diversity, 'the integration-and-learning perspective, the access-andlegitimacy perspective, and the discrimination-and-fairness perspective', and proposed that only the integration-andlearning perspective resulted in the achievement of 'sustained benefits' from diversity. Such a perspective holds that 'the insights, skills and experiences employees have developed as members of various cultural identity groups are potentially valuable resources that the work group can use to rethink its primary tasks and redefine its markets, products, strategies, and business practices in ways that will advance its mission' (Thomas \& Ely, 2001:235). In other words, management operating out of this perspective believe that diversity is desirable not only because it is morally justifiable, nor only because it will ensure access to particular markets, but also because there is inherent value in diversity which should be harnessed in general management and strategic planning within the organisation. When employees of diverse backgrounds sense that they are (or could be) involved in strategic thinking and decision making, they are already sharing in the intangible rewards associated with involvement, and they know that they are more likely to share in the tangible rewards associated with organisational success.

\section{Fairness and transparency}

In order to ensure that the success sharing policy is fair, it is essential that employees feel that they are equipped to capitalise from opportunities within the organisation, and that their performance is fairly assessed. Hence, employees need to have the option of additional training, and they need to know that effective performance management systems are in place. Training and performance management systems are discussed in more depth in the paragraphs that follow.

Generally, training people involves empowering them. The empowerment concept manifests itself at all levels of societal interaction. It is found in giving voice to the disenfranchised, in allowing the weak or marginalised to have access to opportunity needed to forge their own destinies; in allowing every employee the possibility of becoming the producer of his or her own welfare.

In multi-cultural organisations, aside from any functional training requirements, training has to:

1. Build new diversity-interaction skills;

2. Reinforce existing diversity-interaction skills; and

3. Inventory skill-building methodologies.

In addition, diversity-interaction training should, as far as possible, be 'just-in-time'. Just-in-time training means that training must come when the employee - that is, the learner - needs it (Watkins \& Marsick, 1993). People learn best when learning is relevant and useful, and critical information is immediately available.

Performance evaluation feedback enables people to know how they affect each other, and how well they perform their tasks and meet their objectives at work. Feedback ranges from informal comments made about reactions to something others do or say, to formal performance appraisals given to each other. Feedback appropriately given and received empowers the individual by informing him or her how to behave in more effective ways, and thus provides greater choice and focuses his or her efforts (Simons et al., 1993). In addition, supervisor's ratings of subordinates' performance are a key influence on a variety of subsequent human resources actions and outcomes (Judge \& Ferris, 1993).

Performance appraisal of individuals working in teams is a challenge that arises frequently in business. Individual team member performance must be monitored in order to avoid social 'free riding' (e.g., Matsui et al., 1987), that is, the tendency of people to expend less effort when working on a team than they do when working alone. To avoid any negative effects, members must be able to differentiate their contributions from those of other members and perceive a link between their performance and team success (Levine \& Moreland, 1990). Since teams are dynamic and evolve over time, the long-term viability of teams requires adequate performance assessment and feedback mechanisms.

In multicultural organisations, and particularly where people of different race or gender groups have not been employed long enough to have entrenched themselves, the experience of marginality described by Park (1928), and discussed by Human and Van Zyl (1982), could result in additional sensitivity to apparent injustices in rewards. Regardless of how just the performance appraisal and reward systems could be deemed to be by senior management, if the system 
is not transparent, employees perceptions of the justice of the system are likely to differ. Thus, in multicultural organisations particularly, transparent appraisal and reward systems are recommended.

\section{Interaction process: mental models sharing}

The idea of mental model development is straightforward: adherence to a certain pattern of social relationships generates a particular way of viewing the world - that is, a mental model. However, the development of shared mental models requires more lengthy and elaborate periods of interaction (Schein, 1993), and particularly in societies in which social interactions between members of different race or culture groups have been distorted by political or economic conditions.

The guiding principle proposed here is that members of different cultural groups need to have repeated interactions with one another, and the interactions need to be managed such that they result in the establishment of supportive, multicultural social networks. If these two requirements are met in a multicultural workplace, it is proposed that members will communicate more effectively with each other, will be able to foster constructive conflict and, consequently, will begin to understand, trust, respect, and cooperate with one another. The important goal of this process is to enable the group to reach the gradual cocreation of a shared set of meanings and a common thinking process - that is, mental model sharing (Rijamampianina, 1999). The guiding principles proposed here are discussed more fully in the sub-sections that follow.

\section{Repeated interactions}

Interactions may emerge from a wide variety of already established conditions, such as pre-existing friendship ties or resource dependence (Galaskiewicz, 1985). These different starting points vary in the degrees to which the parties are acquainted and have experienced prior interactions. Indeed, in practice, most relationships among strangers emerge incrementally and begin with small, informal deals that initially involve little risk (Friedman, 1991). As these interactions are repeated through time, and meet basic norms of equity and efficiency - that is, they are satisfactory for both parties - they may be able to negotiate, make commitments, and begin to rapidly create and develop a social network.

It is proposed here that, in multicultural organisations, contexts in which repeated formal and informal interactions take place need to be developed by the organisation, to compensate for a reduced likelihood of those interactions taking place across race or culture groups in the absence of such an intervention.

\section{Social networks}

Social networks are produced through an accumulation of prior interactions that are judged by the parties as being efficient and equitable, and that increase the likelihood that parties may be willing to make more significant and risky investments in future interactions (Rijamampianina, 1999). By contrast, repeated failures by individuals to gain confirmation of their perceptions of self in relation to others, set in motion defence mechanisms, which are not likely to lead to congruency in the definition of values, joint purposes, or reliable expectations of one another.

Networking today is no longer simply about meeting colleagues. It is a strategic necessity. Sonnenberg (1990) states that networking is a long-term strategy. Networks improve over time as their staunchest members develop them. They are important vehicles for communication in organisations; thus, they can improve mutual understanding, mutual trust and respect, and cooperation. Nevertheless, they are not developed overnight. Successful networks change and evolve, expand and contract, and must continually be nurtured by all members.

According to Baker (1994), the most productive attitude in a network is what psychologists call 'interdependence' or 'mutual dependence'. It is the recognition that people need each other. It is the recognition that people achieve goals through and with others. Mutual help and cooperation is therefore vitally important. An interdependent person knows that no one is an island (Baker, 1994).

Sonnenberg (1990), however, argues that networking must be a 'give-and-take' relationship because when employees do too much for their colleagues without ever accepting something in return, they make the recipients hesitant to ask for more by implying that they have nothing to offer.

With this norm of generalised reciprocity 'I will do this for you now, in the expectation that somewhere down the road you'll return the favour', Rijamampianina (1999) suggested that:

- Networks increase the potential costs to a defector in any individual transaction since by engaging in opportunism within one transaction, the person places at risk the benefits he or she expects to receive from other transactions in which he or she is currently engaged, as well as the benefits from future transactions;

- Networks facilitate communication and improve the flow of information about the trustworthiness of individuals;

- Networks embody past success at collaboration, which can serve as a culturally defined template for future collaboration.

The business benefits of networking can be substantial, but beyond professional life, networking can provide enormous personal satisfaction and support.

\section{Communication}

Communication is often problematic between people sharing the same language, similar experiences and familiar environments. It is even more so when these factors are not 
shared. Many researchers (e.g., Hayashi, 1989) therefore suggest the use of Intercultural Communication ${ }^{1}$ whenever people belonging to different cultural groups come into contact. Hayashi (1989), for example, proposes the concept of 'Cross-cultural Interface Management' to alleviate strategic problems in culturally mixed organisations.

However, being able to slip into and out of more than one culture is a skill generally restricted to a limited number of individuals. A more practical suggestion for individuals would therefore be to develop a communication network by first taking the step of engaging in repeated interactions, as described above.

Even though the design of the communication network for a team is not always under the control of the members, it is desirable that members have knowledge of these networks in order to facilitate their implementation where and when possible.

\section{Constructive conflict}

Without communication, there can be no question of interpersonal conflict. And without conflict, there can be no question of promoting constructive conflict! ${ }^{2}$ Experts on conflict management have noted that a certain amount of interpersonal conflict is inevitable and perhaps even healthy in organisations (Northcraft \& Neale, 1990). However, conflict becomes destructive when it is excessive, not well managed, or rooted in struggles for power rather than the differentiation of ideas.

The practices of constructive conflict may offer a useful alternative for managing multicultural groups. The constructive conflict approach builds upon the idea that conflict is a key to unlocking the potential in group decision-making. It encourages variety, openness, and challenge. Group decision-making can be improved by constructive conflict practices, because the knowledge and perspectives of all members are tapped and uncritical acceptance of alternatives is prevented (Schweiger, Sandberg, \& Rechner, 1989). In the case of multicultural groups, the constructive-conflict approach could ensure that members, regardless of cultural background, are called upon to contribute and that the inherent diversity of such groups is valued.

Research has supported the benefits of constructive conflict for group decision-making. When constructive conflict is built into the decision-making process, groups:

- $\quad$ Produce assumptions of greater validity and of more importance (Schweiger, Sandberg \& Ragan, 1986);

\footnotetext{
${ }^{1}$ Intercultural Communication is the ability to eliminate communication barriers such as insufficient exchange of information, semantic difficulties, different perceptions among senders and receivers, non-verbal cues that are ignored or misinterpreted, and so on.

${ }^{2}$ Constructive Conflict should not be confused with Competitive Conflict, which discourages both core competence sharing and exploration and can be characterised by win-lose struggles (Tjosvold \& Deemer, 1980).
}

- Make recommendations that more often integrate the ideas and concerns of multiple parties (Tjosvold \& Deemer, 1980) and that are superior in quality (Schweiger et al., 1986) than when harmony or conflict avoidance prevails.

Furthermore, it is the presence of constructive-conflict practices, that is, searching out a variety of perspectives, openly discussing differences, and carefully critiquing assumptions and alternatives, rather than the specific format of debate, that lead to higher quality decision making (Schweiger et al., 1986).

An important question remaining for those who manage multicultural groups is how constructive conflict can be achieved. In his study of conflict-positive organisations, Tjosvold (1991) argues that managers play a key role in setting the norms that encourage work-group members to express their opinions, doubts, uncertainties, and hunches. He advises managers to actively solicit various viewpoints, seek solutions that are responsive to several viewpoints, and reward group successes rather than independent work. Moreover, managers or outside change agents may be required to provide training to familiarise group members with the constructive-conflict approach and to practice its implementation (Schweiger et al., 1986; Tjosvold, 1991).

\section{Mutual understanding}

The formula for managing any relationship involves the same basic elements: mutual understanding and mutual benefit. When there is mutual understanding, each person understands the reasons why the other acts in a particular way and accepts the other's behaviour as legitimate and authentic, despite the tension or inconvenience it might cause (Rijamampianina, 1999). Each person understands the other's motives and feelings; each can assume the role of the other with greater empathy. When there is mutual benefit, both parties achieve benefit from the relationship. Each helps the other. It is a win-win situation (Baker, 1994). It is proposed, therefore, that mutual understanding in multicultural contexts could be effectively fostered through the active encouragement of the development of social networks through repeated formal and informal interactions.

\section{Mutual trust and respect}

Trust, the mutual confidence that no party to an exchange will exploit the other's vulnerability, is today widely regarded as a precondition for success. Mutual trust and respect eases collective life. The greater the levels of trust and respect within a community, the greater the likelihood of cooperation. If trust is absent, no one will risk moving first and all will sacrifice the gains of cooperation in order to remain safe. An area prospers because of the cooperation which trust makes possible, though these same actors regard their mutual confidence as a natural fact (Rijamampianina, 1999). Trust can also be created at will. If the reflexive view of self and society is correct, then the real problem is how trust can be built in particular circumstances through a circuitous redefinition of collective values. It is only by 
recognising their mutual dependence that the actors can define their distinct interests.

In multicultural organisations in which there are clearly identifiable dominant and non-dominant groupings, it appears particularly important for employees to practice expressing respect and positive regard for other employees. When sincere interest is expressed in employees, they are most likely to respond positively. Learned behaviours in racially or culturally segregated societies may inhibit the development of trust and respect, through either intention or ignorance, and a context in which repeated interactions are ensured, and constructive conflict is fostered, is necessary if such behaviours are to be changed (Rijamampianina, 1999). In addition, a long-term orientation encourages trust because the values of short-term gains from untrustworthy actions are reduced. In other words, individuals are more likely to desire a trustworthy reputation when repeated interactions and social networks are common.

\section{Cooperation}

Usually, people believe that cooperation emerges when people find it in their interest to do favours for each other or to assist each other. However, these favours rarely occur simultaneously. Rather, it is a case of 'You do a favour for me now, and I will owe you one.' To sustain this, the future must have a large enough shadow: those who are to cooperate must have enough chance of interacting with, and needing each other again. Therefore, the foundation of cooperation increasingly depends on the durability of the relationship (that is, repeated interactions) and networking (Simons et al., 1993).

Simons et al. (1993) argue that cross-cultural collaboration always implies changes on everybody's part. Working side by side, pursuing the same processes, and producing the same product demands that people create common mental models, which may differ from those they currently have.

\section{Mental models sharing}

An iterative combination of the features of the interaction process described above leads to mental model sharing. A team or a group with a shared mental model is one in which most, if not all of the people involved think about a phenomenon or situation in a very similar manner (e.g., Cannon-Bowers, Salas, \& Converse, 1990). This seems straightforward.

According to Marsick (1994), mental models are not unchangeable; they are the collective creation of people. Therefore they can be changed with the agreement of people. However, he emphasised they have to be made publicly discussible and questionable.

Shared mental models are assumed to enhance the quality of teamwork skills and team effectiveness. Specifically, it is hypothesised that the greater the overlap or commonality among team members' mental models, the greater the likelihood that team members will predict the needs of the task and team, adapt to changing demands, and successfully coordinate activity with one another. Teams that share mental models are expected to have common expectations of their tasks and team members, allowing them to predict the behaviour and resource needs of team members more accurately (Cannon-Bowers et al., 1990).

Shared team models work by virtue of their capacity to allow individual members to anticipate and predict the behaviour of individual members and the probable behaviour of the group (when there is occasion to operate as a group). This capacity, in turn, allows for the efficient and effective use of team members' inputs (Klimosky \& Mohammed, 1994).

Some prior writers argue that decisions can be made in the absence of a team mental model, even when there are differences of interpretation among individuals (e.g., Donnellon, Gray, \& Bougon, 1986). Time pressure, for example, may force a group to arrive at a decision without members sharing perceptions and beliefs on the issues under consideration. It is even possible that team mental models may not emerge until after the decision phase if the team continues to interact and discuss concerns. However, team mental models can have a major influence on the implementation of a decision (providing that the team also has to implement what it has decided on). Teams that have well-developed mental models may be able to implement their decisions more quickly and with fewer problems than teams that do not have collective mental models (Klimosky \& Mohammed, 1994). And in contexts in which cultural differences could be considered to be significant, the negative effects of expedient short-term decision-making could be considerable over the long-term. Shared mental models are ultimately necessary if organisations want to sustain high performance in multicultural contexts, and if they want to be attractive to employees of diverse race or culture groups.

\section{Visioning process: vision sharing}

The essence of a team is shared vision. Block (1987) asserts that managers empower when they create a vision of greatness. However, empowerment will not take place if executives merely create a vision, and then pass it down through successive levels of the organisation to reinterpret and implement. Empowerment occurs through mutual creation of a common vision. Mutual creation implies dialogue and modification of the vision up, down, and across levels. Visioning is a collective process (Watkins \& Marsick, 1993) and empowerment interrupts the status quo.

It is, however, naive to think that co-creation of a vision is easy to achieve without the two preconditions cited above: success sharing and mental model sharing. Members of diverse groups generally experience problems in agreeing on their purpose and on what tasks to perform. To maximise the effectiveness, the manager and team leader must help the group to agree on a vision that transcends their individual differences. When people work together toward a common vision, teams inevitably hold themselves responsible, both as individual members of the team and as the team as a whole. This sense of mutual accountability also produces the 
rewards of mutual achievement shared by all members (Katzenbach \& Smith, 1993).

The power to act must be directed toward something. In a learning organisation, leaders assist people creating a collective vision toward which the entire organisation can work (Watkins \& Marsick, 1993). By learning to share perspectives or mental models, aligned action amongst teams is made possible. A key task in creating the learning organisation is to create alignment by placing the vision in the hands of synergistic teams. These teams need support through the enhancement of their team learning effectiveness and the creation of routine methods to capture and share their learning with the rest of the organisation (Watkins \& Marsick, 1993).

The learning organisation must begin with a shared vision (Watkins \& Marsick, 1993). Learning is directed toward that vision. Learning organisations depend on the participation of many individuals in a collective vision and on the release of the potential locked within them.

\section{Learning process: core competence development}

The idea of the learning organisation is not a new one, but the awareness of core competence development through multicultural learning has only recently surfaced as core competence development has been identified as the hallmark of today's companies (Rijamampianina, 1999).

Individuals should learn if social aggregates are to learn. Managers could involve social units in collective learning aggregates of people who are united by the pursuit of common vision. A collective process - in which core competence is developed - should therefore take place in such a way that social units learn (Prahalad \& Hamel, 1990; Marsick, 1994) and develop core competence.

The challenge is to develop mechanisms to capture, save, and share gains in learning (Ghoshal, 1987; Watkins \& Marsick, 1993). However, up to now, it has not been clear which mechanisms work most effectively and what conditions prompt the access to, and the utilisation of learning. What is known is that capturing and sharing the gains (of learning) depends on the existence of exchange mechanisms (Ghoshal, 1987; Marsick, 1994).
Since ethnic and cultural diversities are 'natural' sources of requisite variety, which is a condition for organisational learning, both managerial and individual learning are crucial elements for developing core competence, thus, successfully managing multicultural organisations.

Here, it is argued that if the above-mentioned pre-conditions - success sharing, mental model sharing, vision sharing are satisfied, an environment that fosters core competence development through multicultural learning can be effectively and easily generated.

\section{Conclusion: toward co-success}

In the past, some literature claimed that cultural diversity leads to lower performance. Studies conducted over the past three decades, (e.g., Cox et al., 1991; Mandell \& KohlerGray, 1990; Thomas \& Ely, 2001) however, agree that, when properly managed, culturally diverse groups and organisations have performance advantages over homogeneous ones. In addition, many writers such as Adler (1991) and Thomas \& Ely (2001) found that the common element among high performing groups with high diversity is the integration of that diversity.

This article proposed a conceptual model and managerial guidelines for the integration of employees' skills and abilities, attitudes and behaviours, knowledge and experiences, through the sharing principle (Figure 2). It suggests that the principle of sharing needs to govern the key organisational processes through a management focus on sharing success, sharing mental models, sharing vision, and sharing competence. It suggested that the application of the sharing principle will facilitate effective multicultural learning and, consequently, will lead to a genuine cosuccess. A word for today's organisations? Share or despair! 


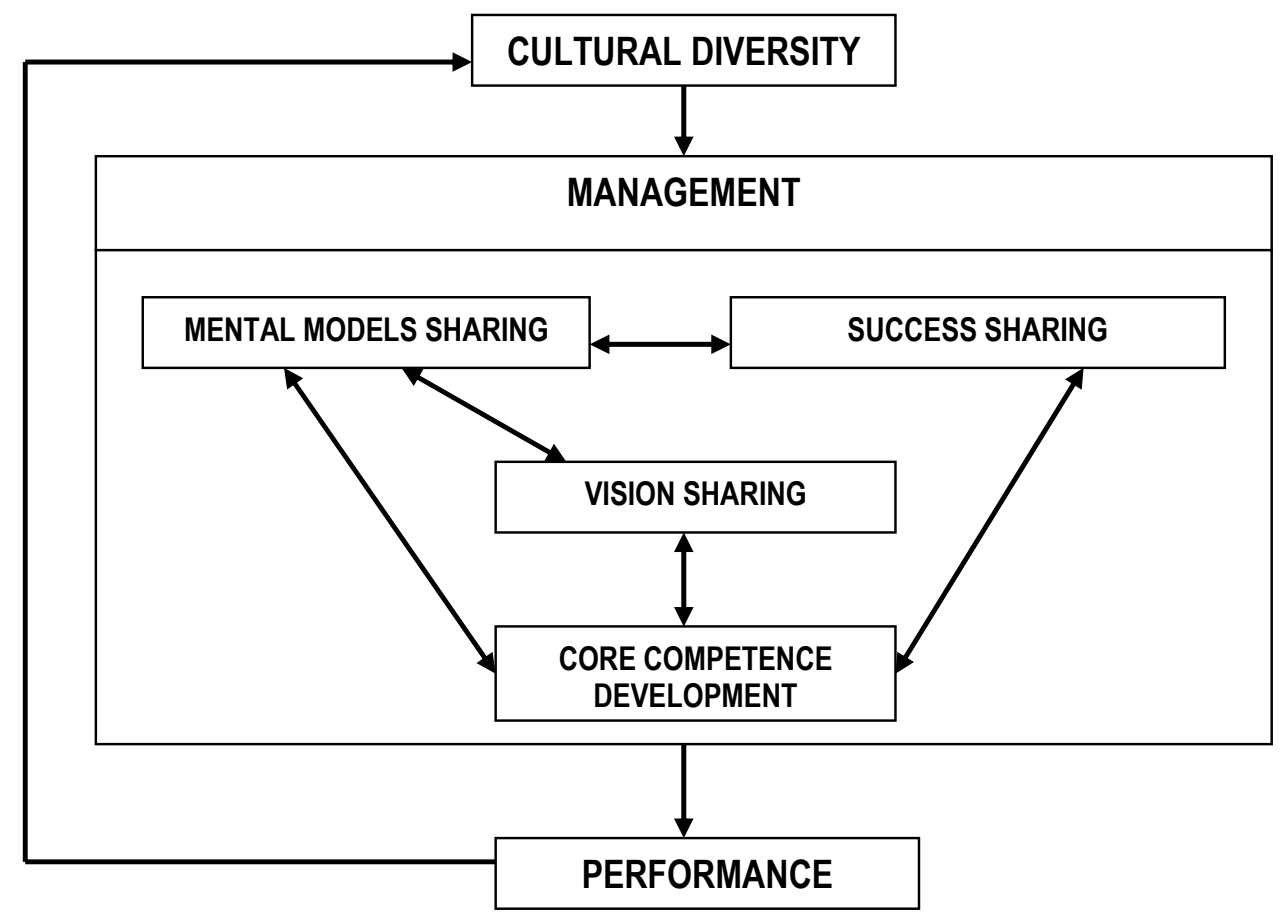

Figure 2: Conceptual framework for effective multicultural

\section{References}

Adler, N. J. 1991. International dimensions of organizational behavior. $2^{\text {nd }}$ Edition. Boston: PWS-Kent.

Baker, W. E. 1994. Networking smart: How to build relationship for personal and organizational success. New York: McGraw-Hill.

Block, P. 1987. The empowered manager: Positive political skills at work. $1^{\text {st }}$ Edition. San Francisco, CA: Jossey-Bass.

Cannon-Bowers, J. A., Salas, E. \& Converse, S. A. 1990. 'Cognitive psychology \& team training: Shared mental models in complex systems', Human Factors Bulletin, 33:14.

Cox, T. H. 1990. 'Problems with research by organisational scholars on issues of race and ethnicity', Journal of Applied Behavioral Science, 26: 5-23.

Cox, T. H. \& Blake, S. 1991. 'Managing cultural diversity: Implications for organizational competitiveness', The Executive, 5(3): 45-56.

Cox, T. H., Lobel, S. A. \& McLeod, P. L. 1991, 'Effects of ethnic group cultural differences on cooperative and competitive behavior on a group task', Academy of Management Journal, 4: 827-847.
D'Iribarne, P. 1986. 'Vers une Gestion Culturelle des Entreprises', Annales des Mines - Gérer \& Comprendre, 4: 77-85.

Donnellon, A., Gray, B. \& Bougon, M. G. 1986. 'Communication, meaning, \& organized action', Administrative Science Quarterly, 31: 43-55.

Evers, H. 1991. 'Optimizing the use of social science knowhow in development cooperation'. In Schönhuth, M. (Ed.). Socio-cultural dimension. Eschborn, Germany: Deutsche Gesellschaft für Technische.

Fenelon, J. R. \& Mergagee, E. I. 1971. 'Influence of race on the manifestation of leadership', Journal of Applied Psychology, 55: 353-358.

Friedman, R. A. 1991. 'Trust, understanding, \& control: Factors affecting support for mutual gains bargaining in labor negotiations.' Paper presented at the Annual Meeting of the Academy of Management, Miami, FL.

Galaskiewicz, J. 1985. 'Interorganizational relations', Annual Review of Sociology, 11: 281-304.

Ghoshal, S. 1987. 'Global strategy: An organizing framework', Strategic Management Journal, 5: 425-440.

Graham-Moore \& Ross, T. L. 1990. Gainsharing: Plans for improving performance. $2^{\text {nd }}$ Edition. New York, NY: BNA Books. 
Hayashi, K. 1989. 'A comparative analysis of cross-cultural interface management: The United States \& Japan.' In Hayashi, K. (Ed.). The U.S. - Japanese economic relationship: Can it be improved? New York: New York University Press.

Hofstede, G. 1984. 'The cultural relativity of the quality of life concept', Academy of Management Review, 9: 389-398.

Human, L. N. \& van Zyl, M. E., 1982. 'Profiles of managers in South Africa'. Course readings. Pretoria: Unisa School of Business Leadership.

Ivanier, D. 1992. 'Qui Se Soucie Encore de la Nationalité des Entreprises?', Annales des Mines - Gérer \& Comprendre, 28: 42-53.

Jaeger, A. M. 1990. 'The applicability of western management techniques in developing countries: A cultural perspective'. In Jaeger, A. M. \& Kanungo, R. N. (Eds.). Management in developing countries. London: Routledge.

James, K. \& Snell, R. 1994. 'The need for creative enquiry for the next millennium', Management Learning, 25(1): 510 .

Judge, T. A. \& Ferris, G. R. 1993. 'Social context of performance evaluation decisions', Academy of Management Journal, 36(1): 80-105.

Katzenbach, J. R. \& Smith, D. K. 1993. 'The discipline of teams', Harvard Business Review, March-April:111-120.

Klimosky, R. \& Mohammed, S. 1994. 'Team mental model: Construct or metaphor?', Journal of Management, 20: 403437.

Levine, J. M. \& Moreland, R. L. 1990. 'Progress in small group research', Annual Review of Psychology, 41: 585-634.

Mandell, B. \& Kohler-Gray, S. 1990. 'Management development that values diversity’, Personnel, 67: 41-47.

Marsick, V. J. 1994. 'Trends in managerial reinvention', Management Learning, 25(1): 11-33.

Matsui, T., Kakuyama, T. \& Onglatco, M. U. 1987. 'Effects of goals \& feedback on performance in groups', Journal of Applied Psychology, 72: 407-415.

Maurice, M., Sellier, F. \& Silvestre, J.-J. 1992. 'Analyse Sociétale et Cultures Nationales: Réponse à Philippe D'Iribarne', Revue Française de Sociologie, 33: 75-86.

McCarrey, M. 1988. 'Work and personal values for Canadian Anglophones and Francophones', Canadian Psychology, 29: 69-83.

Meschi, P. \& Roger, A. 1994. 'Cultural context and social effectiveness in international joint ventures', Management International Review, 34(3): 197-215.
Northcraft, G. \& Neale, M. 1990. Organizational behavior: A management challenge. Chicago: Dryden Press.

Park, R. E. 1928. 'Human migration and the marginal man', American Journal of Sociology, 33(6): 881-893.

Prahalad, C. K. \& Hamel, G. 1990. 'The core competence of the corporation', Harvard Business Review, 68(4): 79-93.

Rijamampianina, R. 1999. Developing core competence through multicultural learning, Universal Publishers.

Ruhe, J. A. \& Allen, W. R. 1977. 'Differences and similarities between black and white leaders', Proceedings of the American Institute of Decision Sciences, Northeast Division:30-35.

Ruhe, J. A. \& Eatman, J. 1977. 'Effects of racial composition on small work groups', Small Group Behavior, 8: $479-486$.

Schein, E. H. 1993. 'On dialogue, culture, \& organizational learning', Organizational Dynamics, 22(2): 40-51.

Schweiger, D. M., Sandberg, W. R. \& Ragan, J. W. 1986. 'Group approaches for improving strategic decision making', Academy of Management Journal, 29: 51-71.

Schweiger, D. M., Sandberg, W. R. \& Rechner, P. L. 1989. 'Experiential effects of dialectical inquiry, devil's advocacy, \& consensus approaches to strategic decision making', Academy of Management Journal, 32: 745-772.

Simons, G. F., Váquez, C. \& Harris, P. R. 1993. Transcultural leadership: Empowering the diverse workforce. Houston: Gulf.

Sonnenberg, F. K. 1990. 'The professional and personal profits of networking', Training \& Development, 44(9): 5560.

Swieringa, J. \& Wierdsma, A. 1992. Becoming a learning organization: Beyond the learning curve. $1^{\text {st }}$ Edition. Wokingham, England: Addison-Wesley.

Tang, S. F. \& Kirkbride, P. S. 1986. 'Developing conflict management skills in Hong Kong: An analysis of some cross-cultural implications', Management Education \& Development, 17: 287-301.

Thomas, D.A. \& Ely, R.J. 2001. 'Cultural diversity at work: The effects of diversity perspectives on work group processes and outcomes', Administrative Science Quaterly, June, 46(2): 229.

Tjosvold, D. 1991. The conflict-positive organization: Stimulate diversity and create unity. $1^{\text {st }}$ Edition. Reading, MA: Addison-Wesley.

Tjosvold, D. \& Deemer, D. K. 1980. 'Effects of controversy within cooperative or competitive context on organizational decision making', Journal of Applied Psychology, 65: 590595. 
Vaid-Raizada, V. K. 1985. 'Management of interethnic conflict in an Indian manufacturing organization', Psychological Report, 56: 731-738.

Watkins, K. E. \& Marsick, V. J. 1993. Sculpting the learning organization: Lessons in the art \& science of systemic change. $1^{\text {st }}$ Edition. San Francisco, CA: JosseyBass.

Watson, W. E. \& Kumar, K. 1992. 'Differences in decision making regarding risk-taking: A comparison of culturally diverse \& culturally homogeneous groups', International Journal of Intercultural Relations, 16: 53-65.

Watson, W. E., Kumar, K. \& Michaelsen, L. K. 1993. 'Cultural diversity impact on interaction process and performance: Comparing homogeneous and diverse task groups', Academy of Management Journal, 36(3): 590-602.

Wilhelm, P. G. 1995. 'Strategies for integrating gainsharing \& restructuring into the post-NAFTA Maquiladora industry', Cross-cultural Management: An International Journal, 2(1): 33-42. 